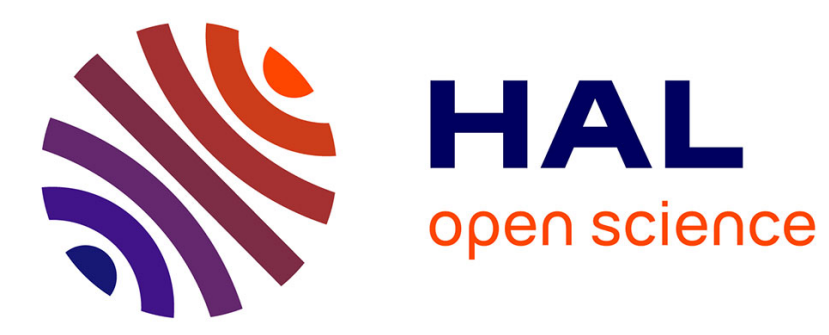

\title{
Successive Generations of Dust in Complex Plasmas: A Cyclic Phenomenon in the Void Region
}

\author{
Marjorie Cavarroc, Maxime Mikikian, Yves Tessier, Laifa Boufendi
}

\section{To cite this version:}

Marjorie Cavarroc, Maxime Mikikian, Yves Tessier, Laifa Boufendi. Successive Generations of Dust in Complex Plasmas: A Cyclic Phenomenon in the Void Region. Physical Review Letters, 2008, 100, pp.045001. 10.1103/PhysRevLett.100.045001 . hal-00239225

\section{HAL Id: hal-00239225 \\ https://hal.science/hal-00239225}

Submitted on 5 Feb 2008

HAL is a multi-disciplinary open access archive for the deposit and dissemination of scientific research documents, whether they are published or not. The documents may come from teaching and research institutions in France or abroad, or from public or private research centers.
L'archive ouverte pluridisciplinaire $\mathbf{H A L}$, est destinée au dépôt et à la diffusion de documents scientifiques de niveau recherche, publiés ou non, émanant des établissements d'enseignement et de recherche français ou étrangers, des laboratoires publics ou privés. 


\title{
Dust Successive Generations in Complex Plasmas: A Cyclic Phenomenon in the Void Region
}

\author{
Marjorie Cavarroc, ${ }^{*}$ Maxime Mikikian, Yves Tessier, and Laïfa Boufendi \\ GREMI, Groupe de Recherches sur l'Energétique des Milieux Ionisés, \\ UMR 6606 CNRS/Université d'Orléans, 14 rue d'Issoudun, BP 6744, 45067 Orléans cedex 2, France
}

(Dated: December 5, 2007)

\begin{abstract}
Dust formation and growth in plasmas are in most cases continuous cyclic phenomena. We show that the growth of new dust generations takes place in a dust free region, usually called void, in the dust cloud. The three-step process of new dust generation is detailed thanks to the correlation between electrical, optical and ex situ diagnostics. The strong inhomogeneity of both the plasma and the dust cloud during this process is underlined.
\end{abstract}

PACS numbers: $52.27 \mathrm{LW}$

Complex (or dusty) plasmas generated in radiofrequency (rf) discharges are widely studied since the 90's. First dust particle observations in processing plasmas were reported by [1] in 1985 for silicon deposition plasmas and by [2] in 1989 in silicon etching plasmas. A first burst of interest has been induced by those contamination phenomena in industrial plasma reactors. Since then, dust particle formation has been widely studied. Silane-based discharges have often been used as "standard systems" to investigate fundamental phenomena and mecanisms involved in dust particle formation and growth, and lots of publications have been produced on this topic (see for example the work of [3-7]). In the 90's the main aim of those studies was to understand dust particle formation to avoid it in industrial reactors. In the 2000's, a second burst of interest has been induced by potential applications of single-crystal and/or polycristalline dust particles. Indeed, single-crystal nanoparticles [8] can be incorporated in thin film layers in order to improve their mechanical and/or optoelectronical properties [9], or used for single electron device fabrication [10]. Dust forming plasmas are also used to produce analog aerosols of planet atmospheres like Titan as demonstrated by [11].

The aim of this paper is to set out the detailed mechanism of formation of dust particle successive generations. We especially show that their growth is a complex spatiotemporal phenomenon closely linked to the void region in the dust cloud. This region has never been clearly attested in spatially confined reactive plasmas due to the reduced optical accesses available to image this region, and to the small size of produced dust particles (giving few laser light scattering signal). The strong inhomogeneity of both the plasma and the dust cloud induced by the growth of dust successive generations can be a significant drawback when performing depositions.

The rf discharge is produced in a grounded cylindrical plasma box $(13 \mathrm{~cm}$ inner diameter and $3.3 \mathrm{~cm}$ for interelectrode distance), enclosed in a vacuum vessel $[4,12]$. The powered electrode is a shower-head one in order to

\footnotetext{
*Electronic address: marjorie.cavarroc@univ-orleans.fr
}

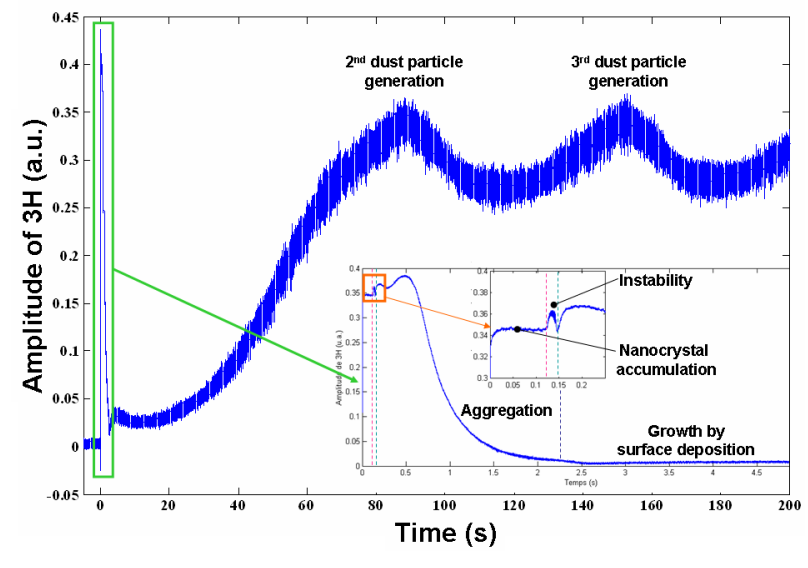

FIG. 1: Time-evolution of the third harmonic of the discharge current amplitude during dust formation for different timescales.

ensure a homogeneous gas distribution at the entrance of the plasma zone. It is connected to a $13.56 \mathrm{MHz}$ rf generator through a matchbox including a blocking capacitor. Typical experimental conditions are: argon-silane mixture $(92: 8)$ with a total pressure around $120 \mu$ bar and a rf power around $10 \mathrm{~W}$. Dust particle formation and growth are monitored through the modifications they induce in the plasma parameters, by following the time evolution of the current third harmonic $(3 \mathrm{H})$ amplitude, that mainly correlates the variation of the free electron density in the plasma [13]. The successive generation process is a continuous phenomenon. As long as silane precursors are provided, new generations of dust are formed in the discharge [14]. From the time evolution of $3 \mathrm{H}$ in figure 1 we can distinguish: (insert) nanocrystal formation and accumulation, aggregation instability $([8,15])$, nanocrystal aggregation and growth by surface deposition, second and third generations.

Successive generations of dust particles appear as quasi-sinusoidal low-frequency oscillations of the $3 \mathrm{H}$ signal, with a period of the order of typically one minute (figure 1). The decrease of $3 \mathrm{H}$ corresponds to a decrease 


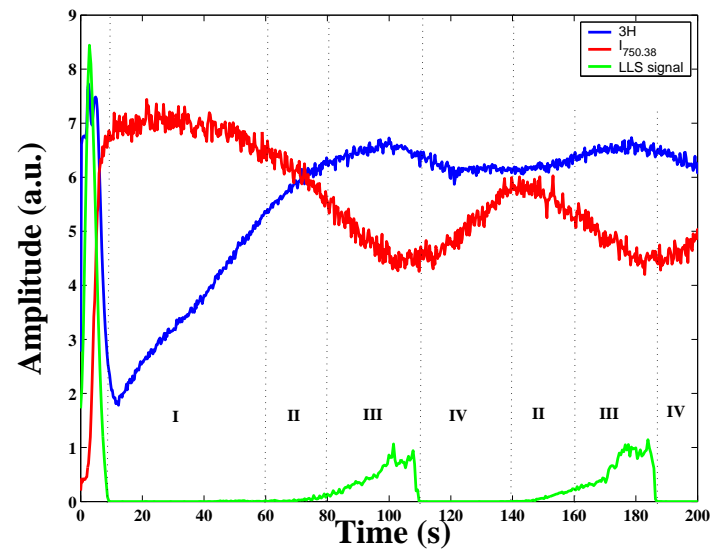

FIG. 2: Time-evolution of $3 \mathrm{H}, \mathrm{I}_{750.38}$ and LLS during dust particle successive generations in an Argon-Silane plasma.

of the electron density: this can be explained both by the presence of big dust particles attaching lots of electrons, or by numerous small dust particles that could produce the same effect. The increase of $3 \mathrm{H}$ corresponds to an increase of the electron density, meaning that less electrons are attached by dust particles: big dust particles could be expelled from the plasma, or the density of smaller dust particles is weak. All classical parameters affecting dust particle formation have an influence on the time-period of these oscillations. As an example, when gas temperature is increased, dust particle formation is delayed and the time-period of these oscillations can rise above several minutes.

Thanks to correlations with Laser Light Scattering (LLS, performed in the plasma center as in [16] using a laser beam and a cooled photomultiplier) and Optical Emission Spectroscopy (OES) of an argon line at 750.38 $\mathrm{nm}\left(\mathrm{I}_{750.38}\right)$, we can refine our hypothesis concerning the behavior of $3 \mathrm{H}$ (see figure 2). For this purpose, we need to assume the presence of a void region in the dust cloud as in [17]. We will see further that this assumption has been experimentally validated.

For the sake of clarity, figure 2 has been divided in several parts numbered from I to IV. The early stages of dust particle formation (between 0 and $10 \mathrm{~s}$ ) have already been discussed previously in [16].

In part I, from 10 to $60 \mathrm{~s}, 3 \mathrm{H}$ increases while $\mathrm{I}_{750.38}$ first increases before reaching a maximum value and then decreases, and there is no detectable LLS signal. The increase in $\mathrm{I}_{750.38}$ corresponds to the opening of a void region, where the ionization rate is enhanced $[18,19]$. This enhancement favors the growth of a new dust particle generation in the void region. Once this new generation started to grow, $\mathrm{I}_{750.38}$ starts to decrease. In this part, new dust particles are neither big enough nor numerous enough to be detected by LLS, so the LLS signal is zero. However, new synthesized dust particles push away bigger ones from the discharge center. The expellation of bigger dust particles, which had attached numerous free electrons, causes an increase of the free electron density in the plasma. Newly created small dust particles attach far less electrons than expelled bigger ones. There is thus a net increase of the free electron density in the discharge, leading to $3 \mathrm{H}$ increase. This confirms the hypothesis of a void opening when $3 \mathrm{H}$ starts to increase [17].

In part II, from 60 to $80 \mathrm{~s}, 3 \mathrm{H}$ exhibits a slope modification and keeps on increasing but more smoothly. $\mathrm{I}_{750.38}$ is still decreasing as in part I and a small increase in the LLS signal is detected. Newly created dust particles grow in the void region and become detectable by LLS. They also start to attach more and more free electrons due to their increasing size. They keep on pushing bigger dust particles away, and tend to fill the whole void region, leading to the decrease of $\mathrm{I}_{750.38}$. As new dust particles become bigger, and so more charged, the balance between free electrons lost by attachment and free electrons recovered due to dust expelling is modified. There is still an increasing amount of free electrons in the plasma, but the net increase is lower than in part I, and thus explain the slope modification in the increase of $3 \mathrm{H}$.

In part III, from 80 to $110 \mathrm{~s}, 3 \mathrm{H}$ increases to its maximum value before starting to decrease. $\mathrm{I}_{750.38}$ decreases to its minimum value, and the LLS signal increases until reaching a plateau. The new generation of grown dust particles is now clearly detected thanks to LLS. This new generation now almost fill the whole void region, leading to the decrease of $\mathrm{I}_{750.38}$ that reaches its minimum value. The net increase in the free electron density is less and less important due to the strong attachment on the growing dust particles, leading $3 \mathrm{H}$ to reach a maximum value. Then, a plateau appears on the LLS signal and $\mathrm{I}_{750.38}$ : the void region is now totally filled by the new generation of dust particles. As these grains are still growing, they keep on attaching more and more electrons, leading to the beginning of $3 \mathrm{H}$ decrease.

In part IV, from 110 to $140 \mathrm{~s}$, the LLS signal suddenly falls to zero, while $\mathrm{I}_{750.38}$ starts to increase. A new void is opening in the discharge center. $3 \mathrm{H}$ decreases until reaching a plateau: an equilibrium is reached between free electrons recovered from dust expellation and free electrons lost by attachment. $\mathrm{I}_{750.38}$ keeps on increasing until a new dust particle generation starts to grow in the void region. The phenomenon is then cyclic and the following part is a new part II, followed by a part III and so on, as long as silane is provided in the discharge.

Voids are dust-free regions in the dust cloud. The assumed mechanism to explain these regions are related to the equilibrium between the inward electrostatic force and the outward ion drag force. Dust voids are still actively studied (see for example [20, 21] and references therein). They are experimentally observed in various dusty plasmas both under microgravity conditions or in the laboratory. They have been observed in sputtering discharges $[19,22-25]$ or with calibrated injected dust particles $[26,27]$. In reactive plasmas, dust voids have not really been observed until now. However, they are 


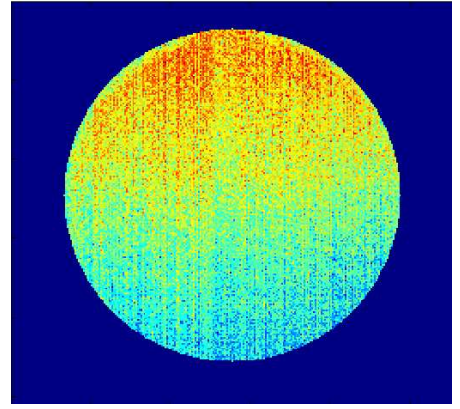

FIG. 3: Typical glow of the discharge during dust formation. The colormap spreads from blue for low intensity to red for high intensity.

strongly suspected in acetylene-based discharges [28], and some features described as "two layers" have already been observed in silane-based plasmas [29]. Moreover, some cases of dust particle successive generations growing in a void region have already been reported in sputtering plasmas $[23,24]$. In reactive gas plasmas, this hypothesis is often made in order to explain experimental results $[17,28]$.

The correlation between $3 \mathrm{H}$, LLS signal and $\mathrm{I}_{750.38}$, presented in figure 2, lets think that a void region could appear in the dust cloud and be the place where a new generation grow. In order to explore the validity of this assumption, we performed several observations of the plasma glow using a CCD camera focused in the plasma center. These experiments were very fussy to perform due to the lack of optical accesses on our reactor. Thus we used a discharge box pierced by a hole of $12 \mathrm{~mm}$ in diameter. Figure 3 shows a typical frame extracted from a movie: the center of the circle hardly corresponds to the center of the discharge, while the dark blue part corresponds to the plasma box. In this figure, a central area of higher glow emission (in red), meaning a higher ionization as well, is evidenced. This result confirms the one previously obtained by optical emission spectroscopy and the void region hypothesis. The assumed void region is off-center. The "red region" is obviously in the upper part of the dust cloud. This effect can be explained by the thermophoretic force on dust particles: the upper electrode is assumed to be $60^{\circ} \mathrm{C}$ while the lower one is at room temperature. The dust cloud is consequently attracted toward the lower electrode, thus exhibiting a void region closer to the upper electrode.

The three-step process assumed in this Letter is related to the formation of new dust particles generations in a void region. This scenario is consistant if an adequate dust particle size distribution is observed in the discharge. For this purpose, spatially resolved depositions have been performed during dust particle successive generations. Five substrates were located on the grounded (lower) electrode in the discharge box. The first one was in the center, and the others were evenly dissevered along

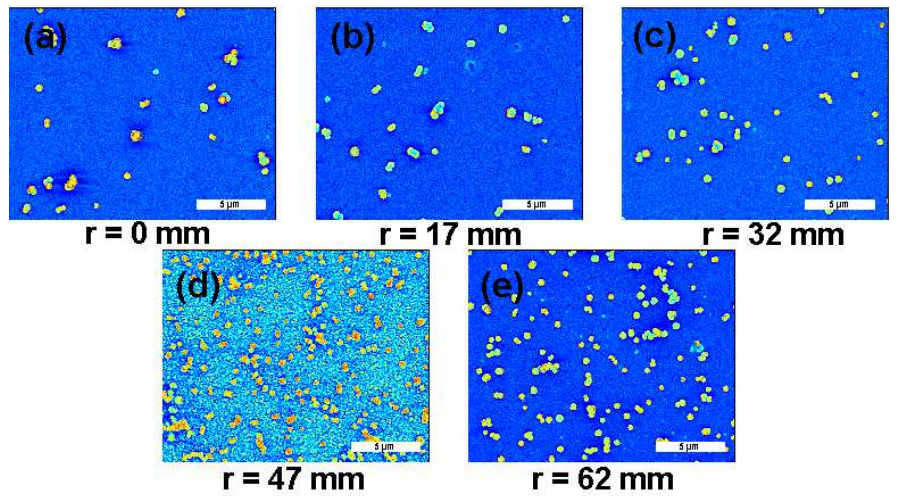

FIG. 4: SEM images of the spatially resolved depositions $($ scale $=5 \mu \mathrm{m})$.

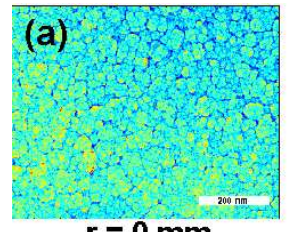

$\mathbf{r}=\mathbf{0} \mathbf{m m}$

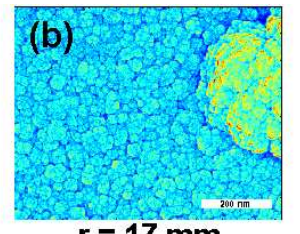

$\mathrm{r}=17 \mathrm{~mm}$

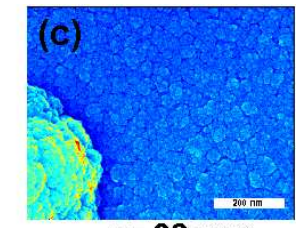

$r=32 \mathrm{~mm}$

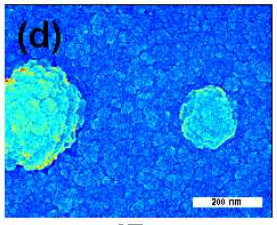

$\mathrm{r}=47 \mathrm{~mm}$

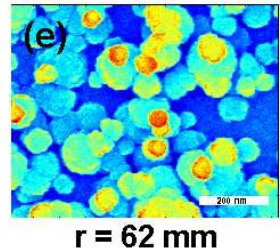

$r=62 \mathrm{~mm}$
FIG. 5: SEM images of the spatially resolved depositions $($ scale $=200 \mathrm{~nm})$.

the electrode radius. These samples have then been observed thanks to Scanning Electron Microscopy (SEM) using different magnifications. In the images with a scale of $5 \mu \mathrm{m}$ (see figure 4), very few big dust particles (between few tens to few hundreds of $\mathrm{nm}$ ) are detected in the discharge center $(\mathrm{r}=0 \mathrm{~mm})$, while more and more are present when the radius is scanned toward the plasma edge $(\mathrm{r}=62 \mathrm{~mm})$. On the other hand, the images with a scale of $200 \mathrm{~nm}$ (see figure 5) indicate that the constitution of the deposited layer is very dependent on its location in the discharge. In the discharge center, the sublayer is made of very numerous nanoparticles around $10 \mathrm{~nm}$ (giving a dense sublayer). The more we go away of the center, the less the sublayer is dense, and its smaller constituents tend to increase in size (up to around 20 $\mathrm{nm})$. These results are totally consistent with a void region, where new dust generations would grow, pushing bigger ones toward plasma edge.

Figure 6 gives a rough sketch of the proposed void region in the $\mathrm{Ar} / \mathrm{SiH}_{4}$ discharge. As proposed in our model, several dust particle populations coexist in the 


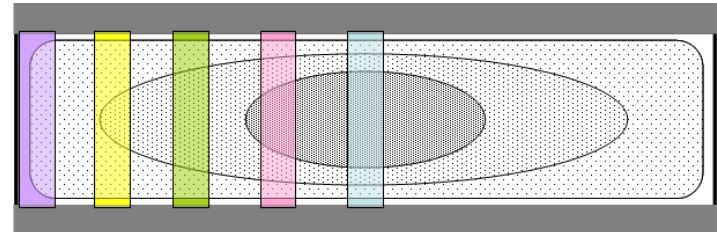

FIG. 6: Model of the void region in the $\mathrm{Ar} / \mathrm{SiH}_{4}$ discharge.

plasma (three in this example). Each new generation grown in the void pushes away the previous one, leading to a concentric structure with the newest dust particles (i.e. smallest ones) in the discharge center, and "shells" made each ones of "older" (i.e. bigger) dust particles. The five colored blocks stand for the volume of deposition on each sample. Thus the collected dust particle populations are consistent with SEM results.

In this paper, thanks to a correlation between the time evolution of the current third harmonic, laser light scattering and optical emission spectroscopy, we brought to the fore the dust cloud dynamics during the growth of dust particle successive generations. It appears that as long as precursors are provided in the discharge, the plasma and the dust cloud never reach a stable state: all plasma parameters oscillate following a cycle that can be resolved in three main steps (refeered as part II, III and IV in the text). We inferred the presence of a void region in a spatially confined argon/silane plasma. This region has already been suspected but has never been rigorously attested before in spatially confined plasmas to the authors' knowledge. Moreover, new dust generations have been demonstrated to grow in this dust free region, pushing previously formed bigger dust particles toward the plasma edge. This last conclusion raises an interesting problem concerning spatially resolved optical measurements usually performed in the plasma center. Due to the presence of a void region in the center, those measurements are not representative of the global behavior of both the plasma and the dust cloud. Then, plasma characteristics or eventual dust presence can be misinterpreted, and correlation with other diagnostics is thus strongly advised. We finally suggest that the described mechanism for the growth of dust successive generations can be extended to the majority of dust forming plasmas.

The authors would like to acknowledge Annie Richard for her precious help in SEM imaging.
[1] R. Roth, K. Spears, G. Stein, and G. Wong, Appl. Phys. Lett. 46, 253 (1985).

[2] G. S. Selwyn, J. Singh, and R. S. Bennett, J. Vac. Sci. Technol. A 7, 2758 (1989).

[3] Y. Watanabe, M. Shiratani, Y. Kubo, I. Ogawa, and S. Ogi, Appl. Phys. Lett. 14, 1263 (1988).

[4] A. Bouchoule, A. Plain, L. Boufendi, J. P. Blondeau, and C. Laure, J. Appl. Phys. 70, 1991 (1991).

[5] C. Böhm and J. Perrin, J. Phys. D: Appl. Phys. 24, 865 (1991).

[6] A. Howling, C. Hollenstein, and P.-J. Paris, Appl. Phys. Lett. 59, 1409 (1991).

[7] E. Stoffels, W. Stoffels, G. Kroesen, and F. de Hoog, J. Vac. Sci. Technol. A 14, 556 (1996).

[8] M. Cavarroc, M. Mikikian, G. Perrier, and L. Boufendi, Appl. Phys. Lett. 89, 013107 (2006).

[9] P. Roca i Cabarrocas, N. Chaabane, A. Kharchenko, and S. Tchakarov, Plasma Phys. Control. Fusion 46, B235 (2004).

[10] S. Tiwari, F. Rana, H. Hanafi, A. Hartstein, and E. F. Crabb, Appl. Phys. Lett. 68, 1377 (1996).

[11] C. Szopa, G. Cernogora, L. Boufendi, J. J. Correia, and P. Coll, Planet. Space Sci. 54, 394 (2006).

[12] L. Boufendi, A. Bouchoule, R. Porteous, J. Blondeau, A. Plain, and C. Laure, J. Appl. Phys. 73, 2160 (1993).

[13] L. Boufendi, J. Gaudin, S. Huet, G. Viera, and M. Dudemaine, Appl. Phys. Lett. 79, 4301 (2001).

[14] A. Melzer, A. Homann, A. Piel, V. A. Schweigert, and I. V. Schweigert, AIP Conference Proceedings 446, 168 (1998).

[15] M. Cavarroc, M. C. Jouanny, K. Radouane, M. Mikikian, and L. Boufendi, J. Appl. Phys. 99, 064301 (2006).

[16] L. Boufendi and A. Bouchoule, Plasma Sources Sci. Technol. 3, 262 (1994).

[17] M.C. Jouanny, Ph.D. thesis, Université d'Orléans (2005).

[18] M. R. Akdim and W. J. Goedheer, Phys. Rev. E 65, 015401 (2001).

[19] M. Mikikian and L. Boufendi, Phys. Plasmas 11, 3733 (2004).

[20] V. Land and W. Goedheer, New. J. Phys. 9, 246 (2007).

[21] M. Kretschmer, S. Khrapak, S. Zhdanov, H. Thomas, G. Morfill, V. F. A. Lipaev, V. Molotkov, A. Ivanov, and M. Turin, Phys. Rev. E 71, 056401 (2005).

[22] G. Praburam and J. Goree, Phys. Plasmas 3, 1212 (1996).

[23] D. Samsonov and J. Goree, Phys. Rev. E 59, 1047 (1999).

[24] M. Mikikian, L. Boufendi, A. Bouchoule, H. M. Thomas, G. E. Morfill, A. P. Nefedov, V. E. Fortov, and the PKENefedov team, New J. Phys. 5, 19 (2003).

[25] M. Mikikian, L. Coudel, M. Cavarroc, Y. Tessier, and L. Boufendi, New J. Phys. 9, 268 (2007).

[26] G. Morfill, H. Thomas, U. Konopka, H. Rothermel, M. Zuzic, A. Ivlev, and J. Goree, Phys. Rev. Lett. 83, 1598 (1999).

[27] A. Lipaev, S. Khrapak, V. Molotkov, G. Morfil, V. Fortov, A. Ivlev, H. Thomas, A. Khrapak, V. Naumkin, A. Ivanov, et al., Phys. Rev. Lett. 98, 265006 (2007).

[28] J. Schauer, S. Hong, and J. Winter, Plasma Sources Sci. Technol. 13, 636 (2004).

[29] J. Dorier, C. Hollenstein, and A. Howling, J. Vac. Sci. Technol. A 13, 918 (1995). 